\title{
What Drives Socially Responsible Design in Organisations?: Empirical Evidence from South Korea
}

\begin{abstract}
This paper presents the results of a study that investigates designers' underlying motivations for socially responsible decision-making within an organisation and identifies the empirical link between the level of designers' awareness of corporate social responsibility (CSR)-related issues, the degree of firms' design management capacities and their perceived performance in terms of socially responsible design (SRD) in organisations. Using large samples targeted across the range of designers in South Korea, the current study empirically supports that SRD decisions are determined in large part by important interaction between the designers' true beliefs and the firm's level of CSR. Our results also show that a firms' design management capacity plays a significant role in integrating environmental and social issues into product and service development and achieving better SRD performance and ultimately CSR goals within organisations.
\end{abstract}

KEYWORDS: socially responsible design (SRD) decision-making, design management capacity, new product and service development processes, ecoentrepreneurship, corporate social responsibility (CSR).

\section{Introduction}

This study empirically explores the role of designers and design managers in corporate social responsibility (CSR) value integration into companies through 
system and product design. Recent scholars have suggested that CSR activities should be holistically integrated in the company's core business and strategic planning process in order to be beneficial for both company and stakeholders (Carroll \& Buchholtz 2008). CSR is considered a company-wide effort, not just a PR exercise, involving activities like manufacturing, processing or even marketing (Green 2010). It is therefore believed that it is critical that every employee understands the company's CSR strategy and how he or she contributes to the success of the initiative. Notably, designers are one of the organisational functions that has the most effect on, and is most influenced, by business practices, in particular, during NPD process. Thus, the design function might be considered a critical partner in making CSR happen.

Whilst there has been much attention given to the need for incorporating consumer and market-related issues into new product development (NPD), little attention has been paid to the inclusion of CSR-related issues and agenda. Furthermore, despite extensive research on design management in the context of marketing and branding in business performance, there has been little discussion about the role and effect of design management capacity on translating the principles of CSR into manufactured goods as well as potential services. Therefore this study undertook research in order to understand how CSR-related issues are embedded within the NPD process especially through design and the way it is managed. This study investigated (i) the underlying motivation of designers' socially responsible decisions in new product development and (ii) influential design management factors affecting the perceived performance of SRD in organisations. The overall aim of this research is to suggests a conceptual framework for SRD, taking into account two major dimensions that 
affect SRD decision-making within an organisational context. This study first uses a theoretical framework of four different types of SRD decision-making and empirically tests whether these dimensions explain a great portion of actual behaviours of designers in SRD decision making in the South Korean context. The findings are then used to develop hypotheses that are empirically tested them to examine the influence of the firm's design management's capacity on the relationship between the level of the designers' awareness of CSR-related issues and their perceived performance of SRD in the companies. Subsequently, the influential design management factors in achieving SRD is unravelled and discussed. Finally, managerial and theoretical implications drawn from the study's findings are suggested.

\section{Theoretical Framework and Hypotheses}

The theoretical background for this research is grounded in (i) the theory of CSR as it provides a conceptual framework for incorporating generic dimensions and constituents underpinning the idea of CSR into an organisation's management and in (ii) the literature on socially responsible design (SRD) and design management with relevant to NPD processes and eco-entrepreneurship, as it provides insights on (a) the role and value of design in addressing the complex problems faced by organisations and society, and (b) how best to turns aspirational societal considerations into the actual products and services through design. The two streams of literature are synthesised to provide a theoretical perspective to guide the empirical exploration of SRD decision-making within the context of organisation. 


\section{The Concept of CSR}

CSR theory claims that the social responsibility of business encompasses the economic, legal, ethical and discretionary expectations that society has of organisations at a given point in time (Carroll 1999), implying that the corporation has not only economic and legal obligations, but also ethical and discretionary responsibilities. CSR also refers to ethical principles that are not necessarily codified by the law (Commission of the European Communities 2001) and entails the obligations arising from the implicit "social contract" between business and society for firms to be not only sensitive to potential harms of their action on various stakeholder groups, but also responsive to society's long-run needs and wants (Kakabadse et al. 2005). CSR theory stipulates that it fits into a 'long-term' perspective, which enables organisation to recognise the interdependencies and synergies between the firms, its stakeholders and society, and therefore seeks to maximise the creation of value simultaneously in economic, social and ecological terms (Rangan et al. 2012; Porter \& Kramer 2011).

Some critics, however, question corporation's fundamental motivation for CSR, arguing that corporate programs to fund social and environmental causes are nothing more than public relations or marketing tools to boost their brand reputation (Moon 2001; Hemingway \& Maclagan 2004). There is also the subtle danger that organisations only 'communicate' on their ethical endeavours while perhaps not driving it through the organisation more generally (Heslin and Ochoa 2008). This can arguably be brought forth by the compartmentalisation or departmentalisation of CSR practices into a range of activities carried out by only a CSR function within an 
organisation as part of the rhetoric of brand management, apart from mainstream business operations (Green 2010). The distinction between the daily practice of each member-for example, in the marketing, design, manufacturing and finance departments-and the communication of CSR policies, therefore, has been the focus of much discussion of CSR in an attempt to ascertain whether the companies 'walk the talk'; design is an integral part of this thinking.

\section{Design as Societal Value: Socially Responsible Design (SRD)}

In the design field since the 1970s there have been continuous attempts by designers to be motivated and interested in enhancing the environmental and social impact of the products they create (Whiteley 1993). In 1971, Victor Papanek provided a powerful critique of the environmental and social problems that design has contributed to, and called for designers to address real problems in the world, such as those of challenged people, the ageing population and the Third World. A growing number of designers since the 1980s have built on Papanek (1971)'s ideas that socially responsible design approaches can have a central and distinct role in the view of market-based design; in particular, the 'market model' and 'social model' of design are no longer considered to be in opposition, as market-oriented design may well respond to ethical, social or environmental needs (Margolin \& Margolin 2002; Moreli 2007). Numerous terms have appeared in the literature of 'socially responsible design (SRD)', which actively embrace the CSR agendas, including ecodesign, design for sustainability, inclusive design, design against crime, and product service system, and all of them appear to reach a common understanding: SRD is a system perspective approach by which design decisions can incorporate the three 
dimensions of financial, environmental, and social issues (Bhamra et al. 2013).

However, the unresolved question related to SRD centres on the legitimacy of socially responsible decision-making within the context of an organisation (Morelli 2007). As in modern societies, formal organisational structures arise in highly institutionalised contexts, the important consideration is what gives designers the rights to act on behalf of non-stockholder constituents, such as consumers, employees, or those who share the firm's physical environment? Whilst the propriety of designers representing shareholders in the design decision making is widely accepted, social and environmental fallout from economic decisions is not likely to be viewed in the same light as is the impact of decisions explicitly made to benefit corporate constituents other than stockholders. This raises some important questions. What actually motivates designers to make SRD decisions in the companies?; How much scope is there for SRD within the context of NPD? Can SRD take place within an institutional context, or must it happen outside the obligations and constraints of a professional relationship?

\section{Designers' Underlying Motivation for Socially Responsible Design(SRD)}

It is clear from the literature that design professionals have the potential to make conscious decisions that affect shareholders, employees, customers, communities and the environment during the new product development process. This means that the amount and quality of the information that is brought to bear on a specific SRD issues will depend on levels of CSR awareness or the altruistic/humanitarian motivations of the chosen individual designer(s). On the other hand, in order to 
harness SRD in an organisational context, understanding the companies' varying degrees of commitment to CSR is also of crucial importance, as different companies have different priorities and management framework in terms of CSR. These differing priorities will affect how CSR, and the importance of CSR is perceived within an organisational context. In this sense, the extent to which CSR is included in the policies of an organisation is a strong indicator of mainstreaming of SRD. It is thus argued that any corporation's commitment to SRD will hinge on the attitudes of its corporate designers (or design managers), but the addition of CSR policies in an organisation would provide a formal reminder that the needs of stakeholder constituents must be considered consistently at each stage and the activities of NPD. Therefore we can advance the theory of SRD with a model of a 'Two-Dimensional Model of Socially Responsible Design (SRD) Decision-Making'.

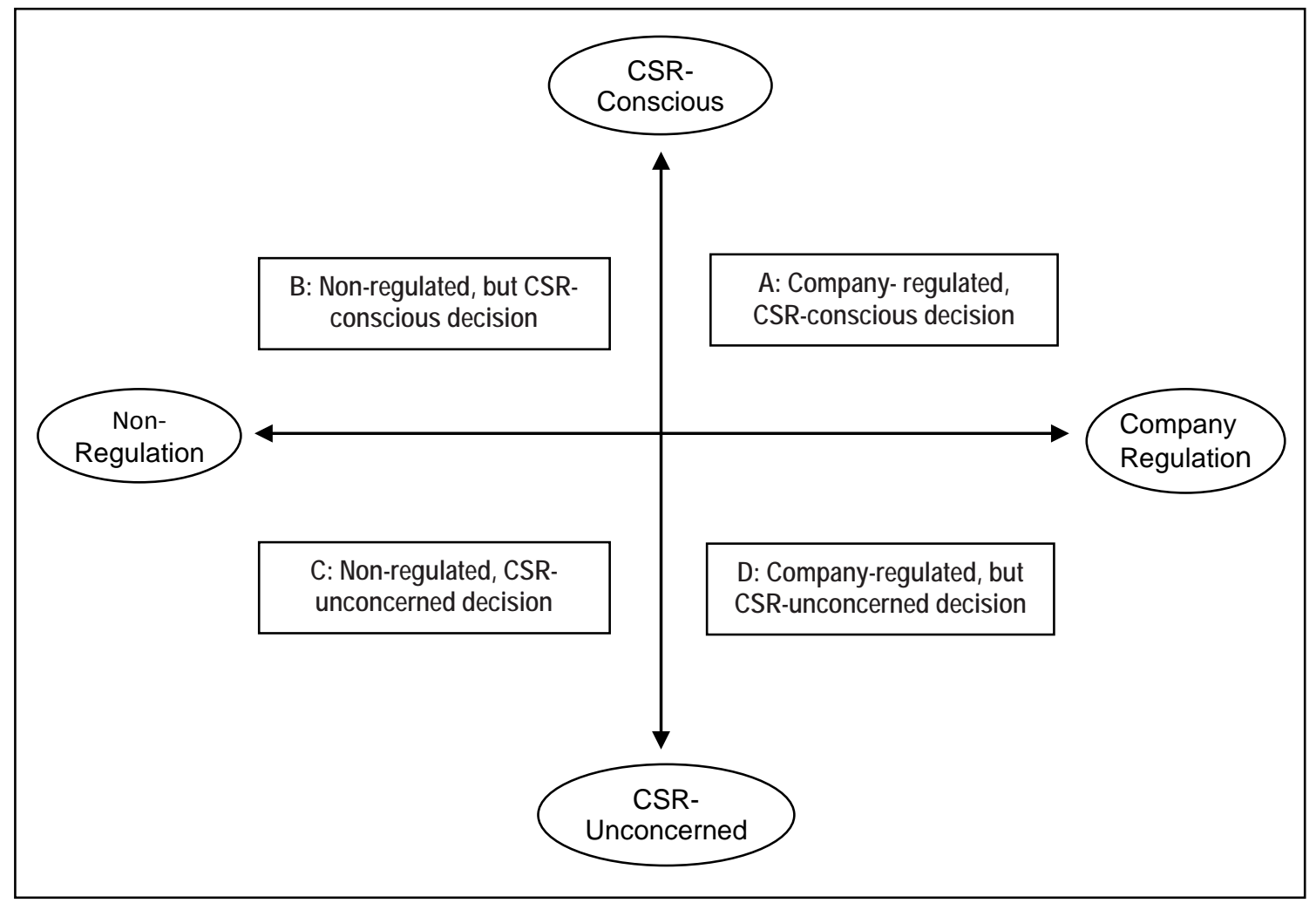

Figure 1 A Two Dimensional Model of SRD Decision-Making 
To empirically assess the current status of SRD decision-making, the model has two axes representing (i) attitudes and actual behaviour of individual designers and (ii) corporate regulation affecting their behavioural attitudes within the context of NPD. The horizontal axis of the framework has two extremes: regulation and nonregulation regarding socially responsible design at the company level. The right hand extreme represents company-regulated (i.e. SRD is part of company's processes, regulation, and policy) SRD decision-making where the designers' responsibility toward customers, local community, and natural environments is perceived in the legitimate sense. By contrast, the left extreme represents non-regulated view of SRD actions where the organisation does not regulate for any aspects of SRD/CSR. The only SRD that would take place is limited to a designer's personal ethical value system. The vertical axis of the model represents two extremes in designers' awareness of the need to develop SRD at individual level, ranging from making a fully conscious design decision in terms of CSR to making a socially unconcerned decision. Thus the model proposed has four distinct quadrants (see Figure 1)

In summary, based on our discussion above and the proposed two-dimensional model of SRD decision making, it is posited that:

H1: The designers' ethical value-driven underlying motivation dimension and company regulation-driven underlying motivation dimension will explain a large portion of different SRD decision-making in the context of NPD.

The Role of Design Management in SRD development

Generally, design management has been more concerned with incremental 
developments and making improvements at an individual project level in terms of specific products and services. However, the role of design management at an enterprise level is now expanding to deal with the complexities involved in business processes and with the radical shift in organisational strategy (Lockwood 2009; Mozota 2006; Jerrard \& Hand 2008). Indeed, integrating CSR initiatives with the strategic design decision-making processes of the firms currently represents a major challenge. In fact, for the vast majority of organisations, SRD represents a transformational philosophy in design and business practices. It indicates significant shift in thinking, attitude and approach from top to bottom across organisations (Cooper et al. 2009). In order to turn the idea of SRD into action, it is thus necessary and important to understand organisational drivers and/or barriers designers face when developing and implementing SRD. A review of the literature in the NPD, design management and eco-entrepreneurship has identified certain key factors as being crucial to the successful integration of SRD indicators into NPD processes and these themes can be grouped at two levels: strategic and operational.

\section{(i) Strategic level}

Strategic level factors can be classified into two groups: (i) corporate strategy and (ii) top management style \& organisational culture. Several research papers examining factors that affect the success and failure of NPD stress that, in order to be successful, NPD must be derived from the corporate goals of the company (Hart 1993). That is, in order to enhance SRD performance, a major challenge for (design) managers is the degree of integration of CSR or SRD principles (such as in the form of strategy objectives, mission and vision, for example) into the overall firm strategy 
(Etzion 2007; Labuschagne et al. 2005). However, many argue that organisations often tend to see CSR as a separate aspect of core strategy. Ramanathan et al.(2010) suggest that some firms have integrated social and environmental considerations by simply adjusting their processes to meet regulations while others have taken a more proactive role through self-regulation and that the latter group of firms are more likely to succeed in introducing sustainable innovations to their processes. The authors thus suggest that integration of CSR visions and missions on the strategic level is a prerequisite for socially responsible business operations, not to mention SRD.

Moreover, the literature review suggests an additional critical success factor: top management leadership \& organisational culture. Top-level corporate leadership is imperative not only to create and define the culture of CSR excellence (Pujari et al. 2004; Swanson 2014), but also to reinforce the importance of corporate commitment to CSR programmes that involve both short-term and long-term benefits and risks (Waldman et al. 2006). Aragón-Correa et al. (2008) have also identified leadership proactivity as one of the relevant variables impacting green innovation performance. Notably, in SMEs, more radical innovation on a process, organisational and product level is often associated with the owner-manager's sustainability vision or commitment to CSR (Swanson 2014). That is, an entrepreneurial approach to solve environmental and social problems evolves into a vehicle for social change, with the socially conscious entrepreneur as change agent.

(ii) Operational level 
At the operational level, we identified three critical focus themes on the agenda of developing socially responsible products and services: (i) design/NPD process activities, (ii) knowledge management and (iii) managing people and network. A number of NPD studies have identified that the efficient execution of both the product development process and activities within the development process is critical to new product success (Cooper et al. 2004). Lockwood (2011), however, advocates that a formal stage-gate process is not commonly used in innovation and design because it often implies separation of involvement. Specifically regarding interfuntional collaboration, Ellram et al. (2008) noted that concurrent engineering can be an important tool for enhancing environmentally responsible practices in companies. Gonzalez-Benito (2008) also mentioned that continuous exchanges among different functions can foster a distinctive characteristic that drives sustainable innovation performance improvements.

To be able to implement SRD, firms also need to have a certain knowledge base. Knowledge is particularly important in the context of the social and environmental challenge which represents fast-moving change and forces that firms need to deal with (Huang and Shih 2009). Especially, in a fast-paced environment, effective knowledge management enables SMEs to stay competitive as a supplier or subcontractor, but also better meet current and future SRD/CSR-related regulations (Michelsen and Fet 2010). Sherman et al. (2005) also found that effective learning from past projects, by reviewing and efficiently using the information that is stored in an organisation, results in improved product performance, particularly in terms of improved prototype development and product launch proficiency. Whilst, Meyers \& 
Wilemon (1989) advocate that, in order to adopt better learning behaviour, firms must first 'unlearn' old ways and perceptions by revealing the inadequacies of current approaches.

Furthermore, literature emphasises the establishment of networks connecting stakeholders, indicating that the success of environmental sustainable innovation can be strongly related to the synergy among supply chain actors (CarrilloHermosilla et al. 2010). De Marchi (2012) also highlights the importance of integrating external stakeholders like suppliers, research institutes and educational institutions, suggesting that such integration is more significant in environmentally sustainable product development processes than in traditional innovation. Similarly Pujari et al. (2004) pointed out that functional interface of environmental specialists with design and product managers affects the environmentally responsive behaviour in new product development.

In brief, current research has identified a number of drivers and barriers of socially and environmentally responsible firms' behaviour. Although there is still much to investigate regarding how these drivers effectively work when designers implement SRD, overall one could expect that firms' level of design management capacity, consisting of these competencies plays an important role in helping designers and design managers implement SRD in a strategic sense.

After introducing our understanding of the organisational drivers as well as based on the two dimensional model discussed above, it is thus hypothesised that: 
H2: Companies will produce a better perceived performance of socially responsible design (SRD) when the designers' knowledge of CSR-related issues is at a higher level.

H3: Companies will produce a better perceived performance of SRD when design management capacity is at higher level.

H4: The perceived performance of SRD, dependent on the level of the designers' knowledge of CSR-related issues, will vary according to the level of design management capacity.

A proposed model is depicted in Figure 2, placing designers' awareness on CSRrelated issues as independent variables and the perceived performance of SRD as a dependent variable. Firms' design management capacity was hypothesised to be a moderator variable on this relationship as well as independent variables at the same time.

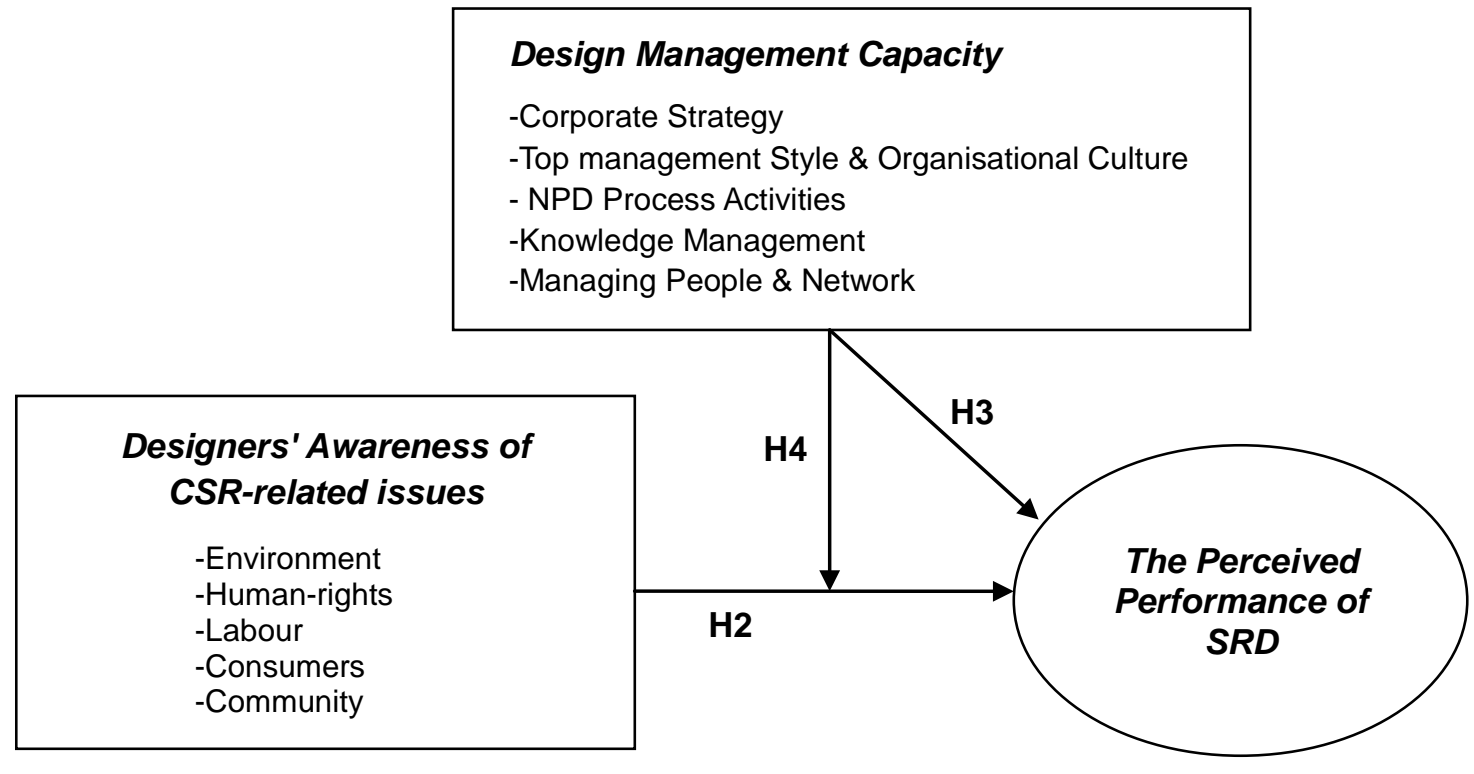

Figure 2 Research Model for this study

(Relationship among designers' awareness on CSR-related issues, design management capacity and the perceived performance of SRD in the companies) 


\section{Methods}

\section{Procedure}

Primary data for hypothesis testing were collected through a survey. A sample of 880 Korean designers and design managers was drawn from the lists of Korean designer groups. Korean designers were selected for this study primary because of the country's status as a newly industrialised one in which large established firms are rapidly globalising and increasingly involved CSR.

To collect data, a structured questionnaire consisting of close-ended questions was developed. To enhance the format, consistency and overall ease of use of the data capture survey, two-phase pre-testing procedures were undertaken with small groups of academics and designers with differing organisational backgrounds and design expertise. The questionnaire comprised five sub-sections to assess: i) general demographics; ii) personal awareness of CSR-related issues; iii) behavioural attitudes toward SRD decision-making; iv) firm's design management competency; and v) their perceived performance of socially responsible design. After multiple follow-up e-mails and phone calls, 316 questionnaires were collected, representing $35.9 \%$ of estimated total distribution. To improve the quality and consistency of the results, only surveys that were fully completed were analysed. 47 incomplete survey were, therefore, not used, so the survey resulted in 269 valid responses: an approximately $30.5 \%$ response rate. Appendix I shows the summary information of the respondents.

\section{Measures}




\section{i) Underlying motivation of SRD}

In order to conceptualise the underlying motivation of SRD, a list of statements were prepared, with either socially/environmentally-conscious or company-regulated design decision-making embedded within them. Sixteen statements were developed based on the literature and the two-dimensional model of SRD. The empirically designed set of questions enables the researcher to uncover designers' behavioural attitudes toward SRD decision-making within their particular context of company regulations. Based upon the two-dimensional model, it was anticipated that attitudinal dimensions could be distinguished as (i) CSR-expressed decision-making; (ii) non-regulated, but CSR-conscious decision-making; (iii) company-regulated, but CSR-unconcerned decision-making; and (iv) non-regulated, and CSR-unconcerned decision-making (see Figure 1).

ii) Awareness of CSR-related issues.

In order to measure informants' awareness of CSR-related issues, the five indicators for CSR: the environment, human-rights, labour, consumers and the communityrelated issues were developed analysing the four influential global standards relating to CSR, namely the International Standards Organisation (ISO); the UN Global Compact (UNGC); the Global Reporting Initiative (GRI); and the Electronic Industry Citizenship Coalition (EICC). Respondents were tasked to rate each one with regard to the importance of each when they are designing. A standard five-point Likert scale was devised for each question (1=very unimportant; 2=unimportant; 3=neutral; 4=important; 5=very important). The results of the respondents' perceived importance of each of five CSR-related issues will be used as independent variables 
to explore a correlation to their performance of SRD.

\section{iii) Design Management Competency}

In order to measure design management competency, a multiple-item scale was used. Respondents were asked to rate the level of their company's design management competency consisting of the five areas: corporate strategy (items based on Etzion 2007; Labuschagne et al. 2005; Ramanathan et al. 2010); top management style and organizational culture (items based on Pujari et al. 2004; Swanson 2014; Waldman et al. 2006; Aragón-Correa et al. 2008); design/NPD process competency (items based on Cooper et al. 2004; Lockwood 2011; Ellram et al. 2008; Gonzalez-Benito 2008); knowledge management (items based on Sherman et al. 2005; Koo and Cooper 2011; Huang and Shih 2009); managing people and network (Carrillo-Hermosilla et al. 2010; De Marchi 2012; Pujari et al. 2004). These five concepts were then utilised as component variables consisting of the design management capacity variable. To maintain consistency in the survey format, the questions concerned were given a five-point interval scale which ranged from (5) denoting "strongly agree" to (1) denoting "strongly disagree". Each aspect of design management capacity measured will be utilised as not only independent variables to explore a correlation to the performance of SRD but also moderator variables to investigate whether the level of design management capacity affects the relationship between designers' awareness of CSR-related issues and their performance of SRD in the organisation.

iv) Perceived Performance of Socially Responsible Design 
To determine respondents' view of the relevant level of their firms SRD performance, a multiple-item scale consisting of 13 questions was used. It examined how they perceive their firms' SRD performance, being divided into three dimensional aspects of SRD, such as the economic (items based on Press \& Cooper 2003; Margolin \& Margolin 2002; Moreli 2007), environmental (items based on Walker 2014; Bhamra \& Lofthouse 2007; Bhamra et al. 2013), and social (items based on Manzini et al., 2008; Cooper et al., 2009; Coleman et al. 2007) performance of SRD, referring to 'three pillars' proposed by Elkington (1998). Since their SRD performance in the organisation was gauged though self-reported evaluation, the term "perceived" was utilised in the prefix position of the variable.

\section{Data Analysis I: Empirical Validation of the Two Dimensional Model of SRD Decision-Making}

Factor Analysis To uncover underlying attitude dimensions, exploratory factor analysis employed. In order to increase interpretability of the findings, a varimax orthogonal rotation, the most common rotation option (Russell 2002), was performed on an initial factor solution. Factor loadings with Eigen values greater than 0.5 were considered relevant to interpretation of the factor and retained subsequent analysis. Factor analysis of the sixteen items on designers' motivation that influence SRD decision-making extracted four factors after varimax rotation. These factors explained $70.56 \%$ of the total variance. The different factors obtained and their respective factor loadings is reported in Appendix II. The factor analysis presented in

Tables 1 and 2 show that two dominant factor have emerged. Factor 1 represents the individual awareness driven approach, emphasising designers' personal ethical 
and moral value system. Factor 2 captures the notion of company regulation-led approach concerned with the perception of SRD in terms of the benefit that flow to business and society. Emergence of the above two leading factors show that these are consistent with the dimensions in the SRD decision-making model developed through the review of existing literature.

\begin{tabular}{cccc}
\hline Component & Total & $\begin{array}{c}\text { \% of total variance } \\
\text { explained }\end{array}$ & Cumulative \% \\
\hline 1 & 3.616 & 22.597 & 22.597 \\
2 & 3.048 & 19.048 & 41.646 \\
3 & 2.563 & 16.017 & 57.662 \\
4 & 2.064 & 12.898 & 70.560 \\
\hline
\end{tabular}

Table 1 Eigenvalues for the Four Factors

Extraction Method: Principal Component Analysis

Quick Cluster The SPSS Quick Cluster procedure was then utilised to classify respondent into meaningful groups in relation to the factors using responses to the specific items as the cluster variables. A "quick cluster" solution based on four clusters of the sixteen items concerned with the underlying motivation toward SRD was carried out. Of 246 respondents, 111 (45.1\%) designers belonged to Cluster 1, representing the most dominant group of designers, while Cluster 2, Cluster 3 and Cluster 4 had 32 designers (13\%), 47 designers (19.1\%), and 56 designers (22.\%), respectively (see Table 2 ).

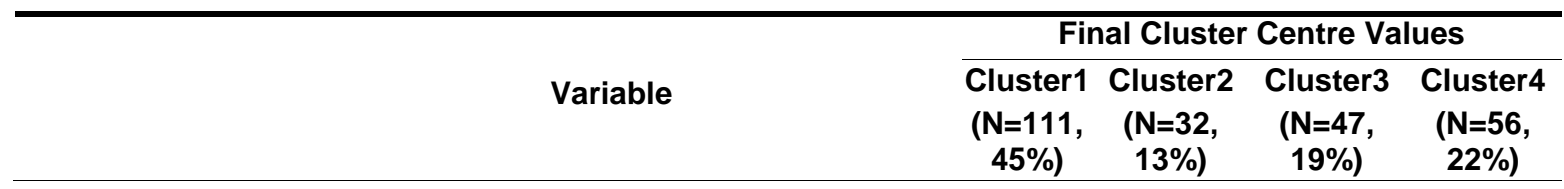

Factor 1 : Designers are personally conscious of developing SRD 
I am personally conscious of the need to reduce

Q01 environmental impact of products and services throughout its life cycle, when I design.

When I design, I try to promote the economic, responsibility to contribute to societal well-being. I personally try to make a design decision that can

lifestyle of customers

$\begin{array}{llll}4.12 & 2.91 & 3.21 & 4.36\end{array}$

When I design, I personally try to develop my

Q04 understanding of how to preserve global ecosystems.

When I design, I am personally aware of the

Q05 importance of design in contributing to social and economic development of the community.

Factor 2 : Company has its own regulation/policy in relation to SRD

\begin{tabular}{|c|c|}
\hline Q09 & $\begin{array}{l}\text { Our company(or client) have corporate } \\
\text { policy/regulation relating to environmental impact } \\
\text { reduction and pollution prevention. }\end{array}$ \\
\hline 10 & $\begin{array}{l}\text { Our company(or client) have corporate } \\
\text { policy/regulation relating to local stakeholder } \\
\text { communication. }\end{array}$ \\
\hline & $\begin{array}{l}\text { Our company(or client) have corporate } \\
\text { policy/regulation relating to promotion of equality and } \\
\text { prevention of unfair discrimination on the basis of } \\
\text { gender, ethnicity, age, class, education, wealth, etc. } \\
\text { Our company(or client) have corporate }\end{array}$ \\
\hline & $\begin{array}{l}\text { policy/regulation relating to promotion of ethical } \\
\text { consumerism. }\end{array}$ \\
\hline
\end{tabular}

Factor 3 : The mass media influence designers' unintended decision making toward CSR

The frequent exposure to crucial social problems

Q13 through the media may lead me to make a designdecision toward caring for the neglected social groups.

The frequent exposure to crucial social problems

Q14 through the media may lead me to make a designdecision for reducing environmental impact of products/services

The frequent exposure to crucial social problems through the media may lead me to make a designdecision for improving quality of life and well-being of the people in local communities.

The frequent exposure to crucial social problems

Q16 through the media may lead me to make a designdecision for promoting responsible marketing communication for consumers

Factor 4 : Organisational communication have indirect impact on designers' SRD decisions

Q06 When I make a design-decision, I am aware of our company's CSR policies.

Effective organisational communication sometimes

Q07 leads me to be indirectly involved in socially responsible design practices.

$\begin{array}{llll}3.48 & 3.19 & 2.64 & 4.21 \\ 3.35 & 3.34 & 2.51 & 4.29\end{array}$




$\begin{array}{llllll} & \text { When I make a design-decision, sometimes } \\ \text { Q08 } & \begin{array}{l}\text { informed by other departments, environmental } \\ \text { considerations are incorporated. }\end{array} & 3.38 & 3.25 & 2.51 & 3.98\end{array}$

Table 2 Final Cluster Centre

An analysis of the final cluster centre reveals that:

Cluster 3 (19.1\%) seems to consists of anti-SRD individuals who do not necessarily consider social responsibility as an integral part of their job responsibility. Cluster 3, for example, represents the group that is in least agreement with all the sixteen statements which are concerned with the underlying motivation for SRD decisionmaking. This is also evident from the fact that the respondents of this group have much lower final cluster values than the median in all statements represented factors $1 \sim 4$.

Cluster 1 (45.1\%) represents designer-driven approach to SRD decision-making. This is evident that the designers belonging to this cluster tend to have high scores, for example on Q1(designers' awareness about environmental issues), Q2 (designers' social responsibility to contributing to societal well-being), Q3 (importance of design in promoting ethical consumerism and sustainable lifestyle) Q4 (personally developing individual understanding about preserving global ecosystems) and Q5 (importance of design in contributing to social and economic development of the community). Conversely, for all statements represented by factors 2, Cluster 1 showed responses that were in least agreement with those statements that represent the company regulation-driven approach to SRD. 
Cluster $4(23 \%)$ comprises a group of respondents who seems to formally undertake SRD through a positive interaction between their personal ethical values and CSR policy of the organisation within their particular context of NPD process. With respect to the relationship between designers' self awareness and the existence of company regulation, the designers belonging to Cluster 4 have the highest scores throughout all the nine statement represented by factors 1 and 2, reflecting a holistic approach to SRD.

Cluster $2(13 \%)$ represents a company regulation-led approach to SRD. This is clear in relation to their reactions to statements represented by factor 1 where they expressed the highest level of disagreement that individual designers personally try to make socially conscious design decisions as well as factor 2 where they tend to have high scores, reflecting the fact that corporations seem to have guidelines and regulations to fulfil minimum CSR criteria in relation to environment (Q9), local stakeholder communication (Q10), promotion of equality and prevention of unfair discrimination (Q11), and promotion of ethical consumerism (Q12).

Figure 3 depicts how the different clusters found in this study are situated on the twodimensional model of SRD decision making proposed by the researchers. 


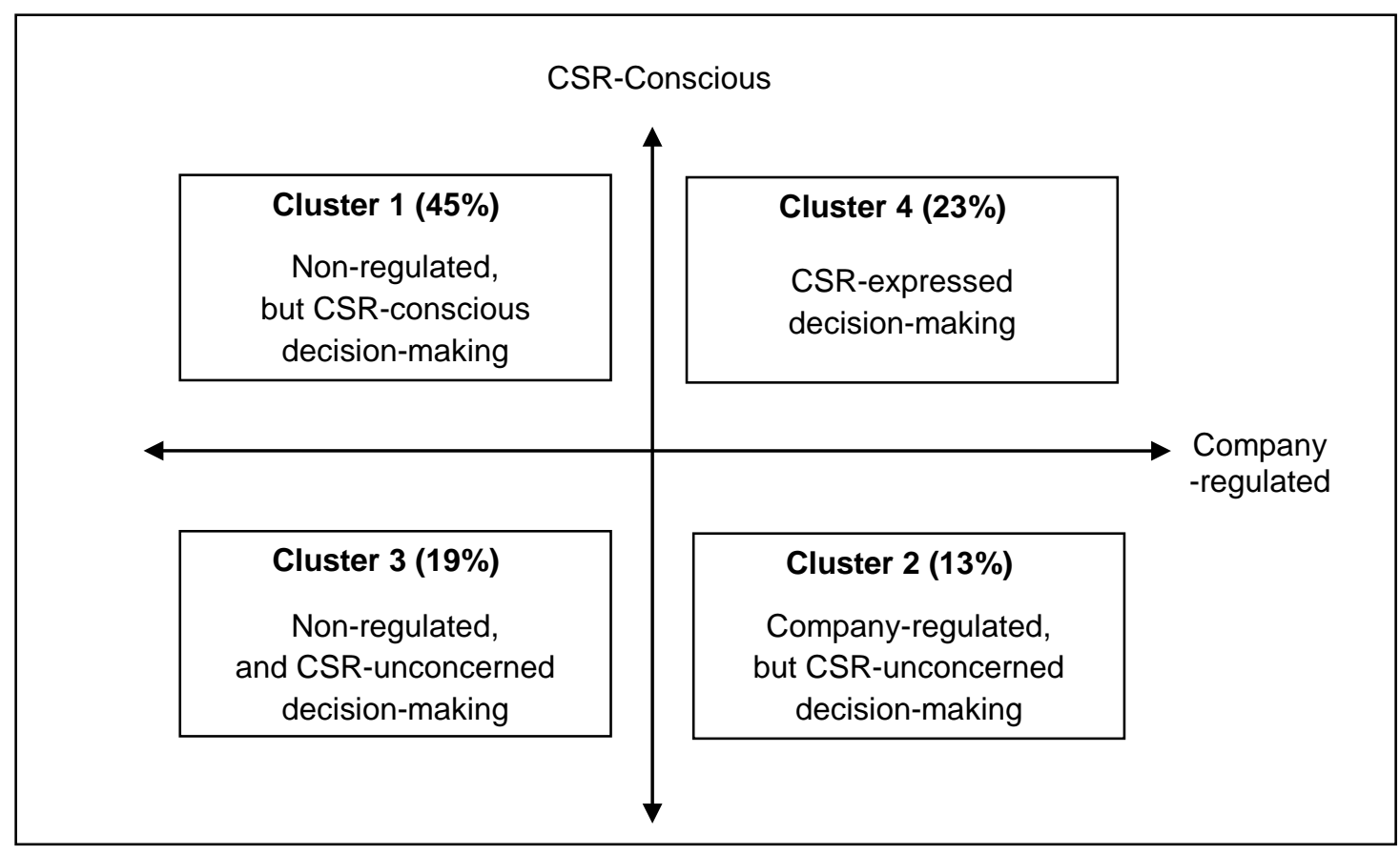

Figure 3 Cluster representation of Korean designers in relation to SRD decision-making in the context of NPD

Findings I : a) confirmation of the two important dimensions of SRD decisionmaking; b) identification of the largest proportion of designers who try to make SRD based on their own insights and knowledge.

The survey findings confirm that the proposed model captures the complexity of SRD decision-making by depicting two important dimensions of SRD decision-making designers' self-awareness of CSR and the company's regulatory efforts to achieve its CSR goals, supporting hypothesis H1. Furthermore, the survey findings highlighted four different groups of designers along with the various attitudinal dimensions to SRD in a Korean context. The result obtained from a quick cluster analysis reveal that in Korea, there is a largest proportion (45\%) of designers who try to make socially conscious design decisions based on their own ethical value system, whilst the group of designers making SRD decisions informed by the company regulation 
and policy is smallest in size.

\section{Data Analysis II: Empirical Analysis of the Influencing Factors of SRD Performance}

As the first phase of survey results have identified, if a large part of SRD decisions depend on the competence and conscientiousness of the chosen individuals, does the level of designers' awareness and knowledge of SRD and personal attributes actually help improve the organisations' performance of SRD? In order to investigate whether the level of the designers' awareness of CSR-related issues, and the degree of design management capacity are positively correlated on the perceived performance of SRD, three regression models are considered. Model 1 uses designers' awareness on CSR issues; Model 2 uses firms' design management capacity only. Model 3 includes the two sets of independent variables at the same time. A comparison between Models 1 and 3 therefore provide a test of whether firms' design management capacity affects relationship between the designers' awareness of CSR-related issues and perceived performance of SRD. Reliability test for all the variable was conducted before using them in subsequent analyses.

To properly investigate the factors influencing the perceived SRD performance, multiple regression analysis was performed for each model and the results for all three models are presented in Appendix III. Overall, the models are significant and provide evidence in support of the three hypotheses $\mathrm{H} 2, \mathrm{H} 3$ and $\mathrm{H} 4$, but to a greater extent with respect to the role of design management in firms pursuing SRD practices. 
Model 1 confirmed that there is a correlation between designers' awareness on CSRrelated issues and perceived performance of $S R D\left(R^{2}=0.051, F=3.840, p<0.01\right)$. In a multiple regression analysis, perceived importance of community and labour were significantly related with perceived performance of SRD. From this model, designers who have a greater degree of awareness of community and labour-related issues were more likely to achieve better-perceived performance of SRD. Yet, this model explained only $5.1 \%$ of the variance in the dependent variable, further requiring reconsideration of the model.

In Model 2, design management capacity was utilised as independent variables. Model 2 is significant $\left(R^{2}=0.503, F=55.141, p<0.001\right)$ and explained over $50 \%$ of the variance in perceived performance of SRD. This model confirmed that a betterperceived performance of SRD occurs when firms' corporate strategy; knowledge management; and people and network management competencies are at higher level.

In Model 3, designers' awareness on CSR-related issues and firms' design management capacity variables were entered all together. The fully specified model had greater explanatory power than the first and second models, accounting for approximately $52.2 \%$ of the variance in the perceived performance of SRD $\left(R^{2}=\right.$ $0.522, F=29.489, p<0.001)$. The statistics signify more than a ten-fold increase in the explanatory power, compared with the explanatory power of 5.1 percent from the first model with designers' awareness variables only. This is, design management capacity variables significantly improved the explanatory power. As Appendix III 
indicates, the four items: perceived importance of labour $(\beta=0.121, p<0.05)$, corporate strategy $(\beta=0.267, p<0.001)$, knowledge management $(\beta=0.228$, $\mathrm{p}<0.001)$, and people and network management $(\beta=0.240, p<0.001)$, were significantly correlated with a better SRD performance, and corporate strategy competency showed the highest degree of association, followed by people and network management. A comparison between Model 1 and Model 3 therefore indicates that the perceived performance of SRD, dependent on the extent of the designers' awareness of CSR-related issues, varies according to the level of firms' corporate strategy; knowledge management; and people and network management competencies, supporting hypothesis $\mathrm{H} 4$.

\section{Variation}

From the three regression models, it is suggested that firms' design management capacity plays a significant role in explaining the percentage of the variance in perceived performance of SRD. However the question remains whether much higher correlation with design management competency over individual factors are now uniform across firms of different sizes or whether large and small/medium sized firms have different priorities about design management areas each other in achieving better-perceived performance of SRD. Therefore, two extensions are additionally made. Two models with different sample section were estimated, using firm size as a control variable: Model 4 uses a group of respondents only from large-sized enterprises; Model 5 targeted mainly at those from medium and small-sized enterprises (SMEs). 
Model $4\left(R^{2}=0.494, F=12.889, p<0.001\right)$ and Model $5\left(R^{2}=0.550, F=17.885\right.$, $p<0.001$ ) both have significant $R^{2}$ values. Model 4 confirmed that in large size firms, corporate strategy; and people and network management were significantly correlated with the perceived performance of SRD. Whilst, in SMEs, the four aspects of top management style and organisational culture; knowledge management; people and network management; and perceived importance of labour contributed to achieving better-perceived performance SRD.

Findings II: a) a high correlation between firms' design management capacity and their perceived performance of SRD; b) differences in focus on specific design management competency areas, between large-sized and small and medium-sized firms

This part has tested the importance of designers' awareness of CSR and design management capacity in SRD achievement. Results indicated that the relationship between designers' awareness of CSR and their perceived performance of SRD was relatively weak, and there was only one aspect of perceived importance of labour as a CSR issue, being significantly related to better SRD performance. On the other hand, there was a high correlation between firms' design management capacity and the SRD performance, yet there was a slight differences in focus on specific design management competency areas, between large-sized and small and medium-sized firms. For example, firms of large size are more likely to achieve better-perceived performance of SRD when corporate strategy competency is at higher level, whilst SMEs are more likely to achieve better-perceived performance of SRD when top management style and organisational culture; and knowledge management 
competencies are at higher level. In all size of firms, people and network management competency has significant relationship with the perceived performance of SRD.

\section{Conclusion and Implications}

Developing socially responsible products and services has become crucial in dealing with the sustainability challenges faced by organisations and society. According to these survey findings, one of the most important impetus for SRD may be attributed to the individual designers' own insights and knowledge. This is consistent with recent studies that suggest designers have taken further responsibility to reflect dimensions of social responsibility when they make decisions (Margolin \& Margolin 2002; Cooper 2005; Moreli 2007). However, this study finds that a higher level of design management capacity yields better performance of SRD than designers' personal attributes. This suggests that product designs were, in practice, motivated for SRD actions more due to the ethos of the individuals as a responsible member of society, rather than an explicit mechanism or actions within the decision-making process. What became clear was that the existing theories on SRD that mainly emphasise the moral responsibility of design for the common good cannot explain the disparity between what corporate designers generally consider to be "socially responsible" in their daily life and what they actually decide to do in a given situation. In conclusion, this study's results have shown that developing SRD should not rely upon individual ethos alone, rather an effective management of organisational process for SRD should be importantly considered from a strategic perspective. From the findings, a number of managerial implications for product development 
professionals and theoretical contributions are suggested.

\section{Managerial Implications}

First, this study's results suggest that corporate strategy plays an important role in the integration of CSR principles into design/NPD process, especially in large sized firms. This is understandable, because well-managed corporate strategy for SRD can generate social and environmental value, while underpinning a company's business objectives and cutting operating costs, and improving relationships with key stakeholders and customers (Driessen \& Hillebrand 2012). This notion implicitly hints at the concept of "eco-efficiency" (e.g., Desimone and Popoff, 2000) which allows firms to pursue sustainability(i.e. reduce energy and material consumption) while at the same time deriving economic benefits from these measures(i.e. reduced costs as a result). Developing consistent coherent corporate strategy, therefore, should be considered from a corporate-level in order to provide a holistic/strategic vision for SRD projects. There are, however, inherent challenges in managing diverse CSR initiatives including SRD cohesively and consistently. Especially for large sized companies that are engaged in a wide range of CSR initiatives, if their various initiatives are managed by separate business units, this is undoubtedly challenging (Middlemiss 2003). In current practice, the typical management of various CSR initiatives by different levels of management and business units has resulted in disparate version of CSR/SRD with little overall cohesion or impact (Werther \& Chandler 2011). It is thus critical for companies to establish a comprehensive CSR/SRD strategy and overarching CSR/SRD vision that can encompass not only in philanthropic efforts, but also in value chain and/or transformative business system 
(Rangan et al. 2012).

Furthermore, in our analysis we observed that in order to empower designers to practice SRD initiatives, strong leadership and support for SRD initiatives at the top level of executive management is critical, especially in SMEs. This requires top management's understanding of the value of design and design management for offering organisations an improved method for social and environmental value creation. It is thus essential that top management find mechanisms to improve for designers' SRD thinking and ability to continue learning around design and CSR. Whilst the scientific view of management often makes it difficult to incorporate the human spirit especially with little room for ethics, or for other fundamentally human considerations such as creativity, trust, initiative, and will (Newkirk \& Freeman 2008), the design-driven approach can help the top manager to step out of his/her prevailing view of the company, inclusive of its core values and review its business from other perspectives (Lockwood 2011; Brown 2009). Particularly, considering the fact that in the case of SMEs, SRD development tended to be strongly ownermanager driven and deliberate strategies are usually not explicitly articulated (Swanson 2014), the entrepreneur's wholehearted association with the new ecological paradigm and fundamental commitment to put nature first and to see to promote human is an essential prerequisite for effective SRD development in SMEs. This factor is closely related to the organisational capability to change its own vision, eliminating cultural barriers that hinder change within the organisation (Schrettle et al., 2014), i.e. in the present case for SRD, the excessive focus on the economical aspect of the NPD project. 
This study also highlights that high levels of internal and external integration are one the most important enabling competences for successful SRD achievement in both large enterprises and SMEs. Besides the issue concerning the need for integration of R\&D, marketing and production areas, the results highlight the importance of interaction with external actors (i.e. customers, suppliers, governments, local authorities, research centres, NGOs etc.) to acquire different types of information in SRD development. For example, environmental-related information from external stakeholders can generate positive outcomes in environmentally oriented innovation projects (Pujari et al. 2004). In interaction with external partners such as universities and research centres, firms, particularly SMEs, can receive support in dealing with the multi-facet nature and complexity of SRD (De Marchi 2012). The inclusion of all stakeholders during the whole process of SRD development strongly influence market acceptance of SRD outcomes (Byrne and Polonsky, 2001). Furthermore, the interaction with unconventional partners (i.e. the local communities, NGOs, etc.) in the NPD process can lead to radical innovations and entirely new business models (Parrish and Foxon 2009). It is therefore necessary that organisations need to place considerable effort on searching for both market and nonmarket stakeholders relevant to their SRD projects and to identify the issues they hold important.

Finally, in this study, it was noted that knowledge creation and knowledge sharing capability in relation to SRD are closely associated with a firm's ability to achieve better SRD performance. Especially, we further find that SRD performance of SMEs could greatly benefit from high levels of knowledge management capacity. For example, to redesign their products and/or adhere to fair trade standards, SMEs may 
benefit from integrating up-to-date technologies and implementing tools such as life cycle analysis to evaluate the environmental hazards and opportunities in (re)designing a product. Furthermore, as the ideas of eco-design is constantly changing; from products of consumption which are naturally degradable to products maintaining their highest value throughout many product life cycles, it is important to ensure that the project team develops its own understanding of SRD from various perspectives. In particular, knowledge gained through even non-commercial projects can flow back into the organisations and provide fertile ground for driving new innovation throughout the company; although it may fail to reap immediate financial gains. It is therefore especially crucial that a company develops a series of pilot programs to explore various SRD ideas, methods, and processes without the normal constraints typically placed on the creation of commercially contracted products and services (Koo \& Cooper 2011).

\section{Theoretical Contributions}

The current research findings advance our understanding of SRD decision-making with the provision of a new theoretical framework. By arguing that individual designers rely on their own perception and behavioural attitude when they make SRD decisions, this model aims to explain how organisational or environmental factors can affect individual designers' socially responsible behaviour and their actual SRD decision-making in an organisational context. Overall, the proposed SRD model allows the organisations to consider the distinct role of design in achieving CSR in the context of the NPD. The key philosophy behind this model is that organisations need to define their own CSR agendas and policies as part of the organisations' 
business strategy, and objectives at a corporate level, and develop its own framework to manage the process of design at a project level to ensure adherence to the specific CSR practices. It places strong emphasis on the systemic linkage between operational- and strategic-levels of design management for the effective development and implementation of SRD in organisations.

The second contribution regards our focus on the South Korean context. Despite the perception that governments in Asia are less involved than governments in other parts of the world in CSR-oriented ethical obligations for firms, this research found a considerable degree of involvement among designers in socially responsible products and service development within an organisation, although there has not been much progress in the realisation of those activities at the corporate level. This research thus increases developed countries' knowledge of CSR and SRD theories practiced in different contexts.

\section{Limitations and Future Research}

The study's results should be also viewed in light of its limitations, which could be addressed by future research. Firstly, the empirical test of the model is based on data arising out of samples drawn from just one country (South Korea, for example). Therefore the results from the study are generalizable across the one country only. However, the future research can test the dimensionality of the designers' underlying motivation for SRD decision-making in cross-cultural context using a larger database comprising a wider range of countries to generalise the model across multiple cultures. Secondly, there are limitations to the analytical techniques used in this 
study. For example, factor analysis is essentially exploratory in character: it impose a rigid structure that contains measurement error and a degree of incompleteness. In summary, for potential future study, heterogeneous quantitative and qualitative samples therefore can be chosen, taking different industrial sectors, cultures, and stakeholder groups, not only designers but also other internal stakeholder groups such as product planners or marketers, engineers, or the senior management team, into account. This may generate sound and credible empirical evidence to facilitate successful adoption of a SRD initiative within the context of NPD in a wide range of organisations from various industry sector, countries, large or small, public or private sector.

\section{Reference}

Aragón-Correa, J. A., et al. (2008) Environmental Strategy and Performance in Small Firms: A Resource-Based Perspective, Journal of Environmental Management , 86(1), 88-103.

Bhamra, T. and Lofthouse, V. (2007) Design for Sustainability: a practical approach, Cooper, R. (series ed.), Gower Publishing Limited, Farnham.

Bhamra, T., Hernadez, R., and Mawle, R. (2013) Sustainability: Methods and Practices. In Walker, S., and Giard, J. (Ed), The Handbook of Design for Sustainability. Bloomsbury Publishing Plc, London.

Borja de Mozota, B. (2006) The Four Powers of Design: A Value Model in Design Management, Design Management Review, 17(2), 44-53.

Brown, T. (2009) Change by Design, HarperCollins Publisher, NY.

Byrne, M. R. and Polonsky, M. J. (2001). Impediments to consumer adoption of sustainable transportation: Alternative fuel vehicles. International Journal of Operations \& Production Management, 21(12), 1521-1538.

Carrillo-Hermosilla, J., et al. (2010) Diversity of Eco-Innovations: Reflections from Selected Case Studies, Journal of Cleaner Production, 18(10-11),1073-1083.

Carroll, A. B. (1999) Corporate Social Responsibility: Evolution of a Definitional Construct. Business and Society, 38(3) (September), 268-295.

Carroll, A. B., and Buchholtz, A. K. (2008) Business and Society: Ethics and Stakeholder Management, 7th edition, South-Western Publishing Co., Cincinnati.

Coleman, R., Clarkson, J., Dong, H. and Cassim, J. (2007) Design for Inclusivity. Gower Publishing Limited, Hampshire. 
Commission of the European Communities (2001) Promoting a European Framework for Corporate Social Responsibilities, COM 366 final, Brussels.

Cooper, R. G., Edgett, S. J., and Kleinschmidt, E. J. (2004) Benchmarking NPD Best Practices II. Research Technology Management, 47(3), 50-59.

Cooper, R. (2005) Ethics and altruism: What constitutes socially responsible design? Design Management Review, 16(3), 10-18.

Cooper, R., Junginger,S., and Lockwood, T. (2009) Design Thinking and Design Management: A Research and Practice Perspective, Design management review, 20(2), 47-55.

De Marchi, V. (2012) Environmental Innovation and R\&D Cooperation: Empirical Evidence from Spanish Manufacturing Firms, Research Policy, 41(3), 614-623.

DeSimone, L. D., and Popoff, F. (2000) Eco-efficiency: The Business Link to Sustainable Development, MIT Press, Cambridge, MA.

Driessen, H. P. \& Hillebrand, B. (2012) Integrating Multiple Stakeholder Issues in New Product Development: An Exploration, Journal of Product Innovation Management, 30(2), 364-379.

EICC(2009) Electronic Industry Code of Conduct, EICC

Elkington, J. (1998) Cannibals with forks : the triple bottom line of 21st century business. Capstone Publishing Ltd., Oxford.

Ellram, L.M., Tate, W., Carter, C.R. (2008) Applying 3DCE to environmentally responsible manufacturing practices, Journal of Cleaner Production, 16 (15), 1620-1631.

Etzion, D. (2007) Research on Organizations and The Natural Environment,1992-present: A Review. Journal of Management, 33(4), 637-664.

GRI (2007). Sustainability Reporting Guidelines 2000-2006, Global Reporting Initiative, Amsterdam.

Green, S. (2010), Good Value: Choosing a Better Life in Business, Penguin.

Gonzalez-Benito, J. (2008) The Effect of Manufacturing Pro-activity on Environmental Management: An Exploratory Analysis, International Journal of Production Research, 46 (24), 7017-7038.

Hart, S. J. (1993) Dimensions of success in new product development, An exploratory investigation, Journal of Marketing Management, 9, 23-41.

Hemingway, C. A., \& Maclagan, P. W. (2004) Managers' personal values as drivers of corporate social responsibility. Journal of Business Ethics, 50(1), 33.

Heslin, P.A. and Ochoa, J.D.(2008) Understanding and developing strategic corporate social responsibility. Organisational Dynamics, 37(2), 125-144.

Huang, P. S., Shih,L. H. (2009) Effective Environmental Management through Environmental Knowledge Management, International Journal of Environmental Science and Technology, 6(1), 35-50.

ISO (2009) Executive briefing on ISO 26000, ISO Management Systems.

Jerrard, R. and Hand, D. (2008) Design and the organisation. In Jerrard, R. and Hand, D. (ed.) (2008), Design Management: Exploring fieldwork and applications, Routledge, London.

Kakabadse, N.K., Rozuel, C. and Lee-Davies, L. (2005) Corporate social responsibility and stakeholder approach: a conceptual review. International Journal of Business Governance and Ethics, 1(4), 277-302. 
Koo, Y. and Cooper, R. (2011) Managing corporate social responsibility through design. Design Management Review. 22(1), 68-79.

Labuschagne, C., Brent, A.C., Van Erck, R.P. (2005) Assessing the sustainability performances of industries, Journal of Cleaner Production, 13(4), 373-385

Lockwood (2009) Design Thinking: Integrating Innovation, Customer Experience, and Brand Value, Allworth Press, NY.

Manzini, E. Walker, S., and Wylant, B. (2008) Enabling Solutions for Sustainable Living, University of Calgary Press, Calgary

Margolin, V., Margolin, S. (2002). A 'Social Model' of Design: Issues of Practice and Research, Design Issues, 18(42), 24-30.

Meyers, P. W. and Wilemon, D. (1989) Learning in new technology development teams. Journal of Product Innovation Management, 6(2), 79-88.

Michelsen, O., and Fet, A. (2010) Using eco-efficiency in sustainable supply chain management; a case study of furniture production, Clean Technologies and Environmental Policy, 12(5), 561-570.

Middlemiss, N. (2003) Authentic not cosmetic: CSR as brand enhancement. Journal of Brand Management, 10(4-5), 353-61.

Moon, J. (2001) Business Social Responsibility: a source of social capital?, Reason in Practice, 1(3), $35-45$.

Morelli N. (2007) Social Innovation and New Industrial Contexts: Can Designers "Industrialize" Socially Responsible Solutions?. Design Issues, 4, 3-21.

Newkirk, D. and Freeman, R. (2008) 'Business as a Human Enterprise: Implications for Education'. In Gregg, S. and Stoner Jr., J. (eds) Rethinking Business Management: Examining the Foundations of Business Education. Princeton, Witherspoon Institute, New Jearsy.

Papanek, V. J. (1971) Design for the Real World: Human ecology and social change, Thames and Hudson, London.

Porter, M. and Kramer, M (2011) Creating Shared Value. Harvard Business Review, 89(1/2), 62-77.

Press, M. and Cooper, R. (2003) The Design Experience: The Role of Design and Designers in the Twenty-First Century, Ashgate Publishing, Aldershot, England.

Pujari, D., Peattie, K., Wright, G. (2004) Organizational Antecedents of Environmental Responsiveness in Industrial New Product Development. Industrial Marketing Management. 33(5), 381-391.

Ramanathan, R., Black, A., Nath, P., Muyldermans, L., (2010) Impact of environmental regulations on innovation and performance in the UK industrial sector, Management Decision, 48(10),1493-1513.

Rangan, K., Chase, L. A. and Karim, S. (2012) Why every company needs CSR strategy and how to build it. Harvard Business School, Working paper 12-088, 1-30.

Russell, D.W. (2002) In search of underlying dimensions: The use (and abuse) of factor analysis. Personality and Social Psychology Bulletin, 28, 1629-1646.

Schrettle, S., Hinz, A., Scherrer-Rathje, M., Friedli, T.(2014) Turning sustainability into action: Explaining firms' sustainability efforts and their impact on firm performance, International Journal of 
Production Economics, 147, 73-84

Sherman, J.D., Berkowitz, D., and Souder, W. E. (2005) New product development performance and the interaction of cross-functional integration and knowledge management. Journal of Product Innovation Management, 22(5), 399-411

Swanson, D. L. (2014) Embedding CSR Into Corporate Culture: Challenging the Executive Mind, Palgrave Macmillan, Hampshire.

UNGC (2008) Corporate Citizenship in The World Economy: United Nations Global Compact, United Nations Global Compact Office, NY..

Waldman, D. A., Sully de Luque, M., Washburn, N., and House, R. J. (2006) Cultural and Leadership Predictors of Corporate Social Responsibility Values of Top Management: A GLOBE Study of 15 countries. Journal of International Business Studies, 37, 823-37.

Walker, S.(2014) Designing Sustainability: Making radical changes in a material world, Routledge, NY

Werther, W. B. and Chandler, D. (2011) Strategic Corporate Social Responsibility: Stakeholders in a Global Environment, 2nd edition, Thousand Oaks, Sage, CA

Whiteley, N. (1993) Design for Society, Reaktion Books Ltd, London. 
Appendix I. Descriptive Information of Sampled Designers

\begin{tabular}{|c|c|c|}
\hline & No. of designers & $\%$ of sample \\
\hline \multicolumn{3}{|l|}{ Gender } \\
\hline Male & 115 & 42.8 \\
\hline Female & 154 & 57.2 \\
\hline \multicolumn{3}{|l|}{ Age } \\
\hline $18-24$ & 4 & 1.5 \\
\hline $25-30$ & 111 & 41.3 \\
\hline $31-40$ & 141 & 52.4 \\
\hline $41-50$ & 10 & 3.7 \\
\hline $51-60$ & 3 & 1.1 \\
\hline \multicolumn{3}{|l|}{ Highest education level } \\
\hline High School/GED & 1 & 0.4 \\
\hline Diploma or Foundation Degree & 24 & 8.9 \\
\hline Bachelor's Degree & 177 & 65.8 \\
\hline Master's Degree & 63 & 23.4 \\
\hline Doctorial Degree & 4 & 1.5 \\
\hline \multicolumn{3}{|l|}{ Type of organisation } \\
\hline Company & 145 & 53.9 \\
\hline Design agency & 124 & 46.1 \\
\hline \multicolumn{3}{|l|}{ Size of organisation } \\
\hline Large & 125 & 46.5 \\
\hline Medium & 55 & 20.4 \\
\hline Small & 59 & 21.9 \\
\hline Micro & 30 & 11.2 \\
\hline \multicolumn{3}{|l|}{ Industrial sector } \\
\hline Product-orientated & 113 & 43.1 \\
\hline Service-orientated & 149 & 56.9 \\
\hline \multicolumn{3}{|l|}{ The number of designers } \\
\hline Less than 10 & 108 & 40.1 \\
\hline $10-20$ & 74 & 27.5 \\
\hline $21-30$ & 21 & 7.8 \\
\hline $31-50$ & 11 & 4.1 \\
\hline Over 50 & 55 & 20.4 \\
\hline \multicolumn{3}{|l|}{ Field of design } \\
\hline Industrial design & 68 & 25.3 \\
\hline Communication design & 105 & 39.0 \\
\hline Environmental design & 54 & 20.1 \\
\hline Design strategy/product planning & 36 & 13.4 \\
\hline Others & 6 & 2.2 \\
\hline \multicolumn{3}{|l|}{ Position } \\
\hline Junior level & 170 & 63.2 \\
\hline Senior level & 66 & 24.5 \\
\hline Director of department & 20 & 7.4 \\
\hline Board member & 13 & 4.8 \\
\hline \multicolumn{3}{|l|}{ CSR education participation } \\
\hline Yes & 106 & 39.4 \\
\hline No & 163 & 60.6 \\
\hline
\end{tabular}




\section{Appendix II. Rotated Component Matrix}

\begin{tabular}{|c|c|c|}
\hline $\begin{array}{c}\text { Question } \\
\text { No. }\end{array}$ & Statements & $\begin{array}{c}\text { Factor } \\
\text { Loadings }\end{array}$ \\
\hline
\end{tabular}

\section{Factor 1 : Designers are personally conscious of developing SRD}
Q01 I am personally conscious of the need to reduce environmental impact of products and services throughout its life cycle, when I design.
When I design, I try to promote the economic, social, and cultural rights of
Q02 vulnerable groups based on my awareness of the designers' social responsibility to contribute to societal well-being.
Q03 I personally try to make a design decision that can promote ethical consumerism and sustainable lifestyle of customers global ecosystems.
Q05 When I design, I am personally aware of the importance of design in contributing to social and economic development of the community.

Factor 2 : Company has its own regulation/policy in relation to SRD
Q09 Our company(or client) have corporate policy/regulation relating to environmenta impact reduction and pollution prevention.
Q10 Our company(or client) have corporate policy/regulation relating to local stakeholder communication.
Our company(or client) have corporate policy/regulation relating to promotion of equality and prevention of unfair discrimination on the basis of gender, ethnicity, age, class, education, wealth, etc.
Q12 Our company(or client) have corporate policy/regulation relating to promotion of ethical consumerism.

Factor 3 : The mass media influence designers' unintended decision making toward CSR

Q13 The frequent exposure to crucial social problems through the media may lead me to make a design-decision toward caring for the neglected social groups.

Q14 me to make a design-decision for reducing environmental impact of products/services

The frequent exposure to crucial social problems through the media may lead me to make a design-decision for improving quality of life and well-being of the people in local communities.

The frequent exposure to crucial social problems through the media may lead me to make a design-decision for promoting responsible marketing communication for consumers

Factor 4 : Organizational communication have indirect impact on designers' SRD decisions

Q06 When I make a design-decision, I am aware of our company's CSR policies.

Q07 Effective organisational communication sometimes leads me to be indirectly

Q08 involved in socially responsible design practices.

(Extraction Method: Principal Component Analysis-Rotation Method: varimax with Kaiser Normalization) 
Appendix III. Multiple Regression on the Influencing Factors for SRD Performance

\begin{tabular}{|c|c|c|c|c|c|}
\hline & Model 1 & Model 2 & Model 3 & Model 4 & Model 5 \\
\hline & $\begin{array}{c}\text { Designers' } \\
\text { awareness } \\
\text { only }\end{array}$ & $\begin{array}{c}\text { DM } \\
\text { Capacity } \\
\text { only }\end{array}$ & $\begin{array}{c}\text { Designers' } \\
\text { awareness } \\
+ \\
\text { DM } \\
\text { Capacity }\end{array}$ & $\begin{array}{c}\text { Designers' } \\
\text { awareness } \\
+ \\
\text { DM } \\
\text { Capacity } \\
+ \\
\text { Large size firms }\end{array}$ & $\begin{array}{c}\text { Designers' } \\
\text { awareness } \\
+ \\
D M \\
\text { Capacity } \\
+ \\
\text { Small \& medium size } \\
\text { firms }\end{array}$ \\
\hline \multicolumn{6}{|l|}{$\begin{array}{l}\text { Designers' awareness } \\
\text { of CSR-related issues }\end{array}$} \\
\hline $\begin{array}{l}\text { Perceived importance of } \\
\text { Environment }\end{array}$ & $\begin{array}{r}0.020 \\
(0.027)\end{array}$ & & $\begin{array}{r}-0.028 \\
(-0.037)\end{array}$ & -0.038 & -0.032 \\
\hline $\begin{array}{l}\text { Perceived importance of } \\
\text { Human right }\end{array}$ & $\begin{array}{r}-0.011 \\
(-0.015)\end{array}$ & & $\begin{array}{r}-0.013 \\
(-0.017)\end{array}$ & -0.018 & 0.014 \\
\hline $\begin{array}{l}\text { Perceived importance of } \\
\text { Consumers }\end{array}$ & $\begin{array}{r}-0.051 \\
(-0.054)\end{array}$ & & $\begin{array}{r}-0.054 \\
(-0.058)\end{array}$ & -0.010 & -0.081 \\
\hline $\begin{array}{l}\text { Perceived importance of } \\
\text { Community }\end{array}$ & $\begin{array}{l}0.113^{\star} \\
(0.145)\end{array}$ & & $\begin{array}{r}0.019 \\
(0.024)\end{array}$ & 0.079 & -0.039 \\
\hline $\begin{array}{l}\text { Perceived importance of } \\
\text { Labour }\end{array}$ & $\begin{array}{l}0.117^{\star \star} \\
(0.175)\end{array}$ & & $\begin{array}{l}0.081^{*} \\
(0.121)\end{array}$ & 0.084 & $0.090 *$ \\
\hline \multicolumn{6}{|l|}{$\begin{array}{l}\text { Design Management } \\
\text { capacity }\end{array}$} \\
\hline Corporate strategy & & $\begin{array}{l}0.216^{\star \star \star} \\
(0.274)\end{array}$ & $\begin{array}{l}0.210^{\star * *} \\
(0.267)\end{array}$ & $0.305^{\star \star \star}$ & 0.115 \\
\hline $\begin{array}{l}\text { Top management style \& } \\
\text { organizational culture }\end{array}$ & & $\begin{array}{r}0.080 \\
(0.108)\end{array}$ & $\begin{array}{r}0.079 \\
(0.108)\end{array}$ & -0.001 & 0.126 * \\
\hline NPD process activities & & $\begin{array}{r}0.010 \\
(0.013)\end{array}$ & $\begin{array}{r}0.001 \\
(0.001)\end{array}$ & 0.044 & 0.004 \\
\hline Information management & & $\begin{array}{l}0.159 * \star \\
(0.194)\end{array}$ & $\begin{array}{l}0.185^{\star \star \star} \\
(0.228)\end{array}$ & 0.150 & 0.256 *** \\
\hline $\begin{array}{l}\text { People and network } \\
\text { management }\end{array}$ & & $\begin{array}{l}0.213^{\star \star *} \\
(0.265)\end{array}$ & $\begin{array}{l}0.191^{\star \star \star} \\
(0.240)\end{array}$ & $0.218 * *$ & 0.144 * \\
\hline F-values & $3.840 * \star$ & $55.141^{\star * *}$ & $29.489 * \star \star$ & $12.889 * * \star$ & $17.885^{\star * *}$ \\
\hline Adjusted $\mathrm{R}^{2}$ & 0.051 & 0.503 & 0.522 & 0.494 & 0.550 \\
\hline
\end{tabular}

Note 1: * $\mathrm{p}<0.05 ;{ }^{* \star} \mathrm{p}<0.01 ;{ }^{* \star *} \mathrm{p}<0.001$

Note 2: R-squared - Percentage of variance explained

Note 3: Standardized coefficients are in brackets; the estimates of the standardized coefficients could be used to compare the relative effects of two or more explanatory variables 


\title{
Dr. Yoori, Koo \\ Assistant Professor of Design Theory \\ College of Fine Arts \\ Hongik-University \\ 94 Wausan-ro, Mapo-gu, Seoul, 04066, South Korea
}

Yoori Koo is a visual communication designer, researcher and educator. Her PhD in design management was completed at the Lancaster University, in which she investigated how design and human-centred design thinking might lead to more sustainable products and services in organisations. Her work brings new and important insights to the existing literature - especially on the role of design management and the importance of organisations taking seriously the critical contemporary issues of Corporate Social Responsibility and Sustainability. She is Assistant Professor at Hongik-University in South Korea, and a Public Service Design Consultant in the Ministry of Security and Public Administration, also South Korea.

Email: yrkooc@gmail.com

\author{
Rachel Cooper OBE \\ Distinguished Professor of Design Management and Policy \\ Director of ImaginationLancaster \\ Lancaster Institute for the Contemporary Arts \\ Lancaster University \\ Bailrigg, Lancaster \\ LA1 4YW, UK
}

Rachel Cooper OBE is Distinguished Professor of Design Management and Policy at Lancaster University. She is Director of ImaginationLancaster, an open and exploratory design-led research centre conducting applied and theoretical research into people, products, places and their interactions. Professor Cooper's research interests cover: design thinking; design management; design policy; and across all sectors of industry, a specific interest in design for wellbeing and socially responsible design. She has published extensively on these topics, including books 'Designing Sustainable Cities' and 'Constructing Futures' (Wiley Blackwell). She is also series editor of the Ashgate series Design for Social Responsibility covering topics such as designing for sustainability, inclusivity, service design, sport, health, transport and policy. She is currently working on Liveable Cities, an Engineering Physical Sciences Research Council funded six-year research programme working to identify design and engineering solutions that will lead to low-carbon, resource-secure, future cities in which societal wellbeing is prioritised. Also 'The Creative Exchange', an Arts and Humanities Research Council Knowledge Exchange hub looking at the growth of the creative industries through exploring the 'digital public space'. She was a member of the 2014 Blackett review on the Internet of Things. She is a non-executive Director of the Future Cities Catapult, and a Lead Expert for the UK Government Foresight programme on the Future of Cities, and is on the UK Academy of Medical Sciences Working group addressing 'the health of the public 2040'.

Email: r.cooper@lancaster.ac.uk 